Letras, Lima 48 (82-83): 32-42, 1976.

\title{
El pensamiento de San Agustín
}

ANTONio PENa CABRERA

Quisiera examinar el pensamiento de San Agustín a la luz de dos ideas que en mi concepto son claves: la creación y la trascendencia. La primera tiene que ver con el tiempo, pues el concepto de creación se explicita racionalmente mediante el esclarecimiento - como lo hace San Agustín- de la naturaleza del tiempo. La segunda plantea el próblema de la alteridad y la distancia abisal entre Dios y el mundo, el creador y la criatura. A la luz de estas dos ideas entenderemos mejor el movimiento dialéctico del pensamiento agustiniano que se distiende permanentemente entre la temporalidad y la interioridad, la nada y el ser, el pecado y la gracia. Se ha dicho y se repite que San Agustín no es un pensador sistemático. indo que indudablemete se está en lo cierto. Pero se olvida agregar que es un pensador coherente, cuyo pensamiento gira alrededof de intuiciones e inquietudes muy precisas, que trataremos de destacar en esta ocasión.

\section{La Creación}

La idea de creación se ha recogido indudablemente de la Biblia, pero es dudoso que signifique en la tradición judía "creación de la nada". Pfeiffer (Intr. to the old testament, N. Y., 1948, pp. 192-194) nos dice que el códice Priestley, cuyo contenido es el que nos entregan las actuales ediciones de la Biblia, fue redactado alrededor del s. V a. C. y que está elaborado sobre la base de escritos más antiguos, probablemente de un poema no israelí. Según este substratum, el caos, el océano y la oscuridad existían antes del trabajo de la creación. La palabra bãra, que significa "creación" en hebreo, no aparece en el substratum, pero está en la parte más reciente del Isaías y significa sólo "actividad divina sin esfuerzo". Por estas razones Pfeiffer concluye que es muy dudoso que en el Códice Priestley creación signifique creatio ex 
nihilo y no más bien creación a partir de materiales ya existentes. (loc. cit.).

El concepto de creatio ex nihilo tampoco aparece en el pensamiento griego clásico ni en el helenístico-romano. Recordemos sólo que para Platón hay el demiurgo, ser intermediario entre las ideas (arquetipos) y la materia eterna. De modo que la creación se reduce a la modelación del cosmos a partir de preexistencias: las ideas y la materia. La Filosofía aristotélica - de nula o escasa influencia en la conformación del dogma cristiano de la época patrística, a no ser a través del neoplatonismo- postula un Dios motor-inmóvil, pero que antes que causa eficiente es el fin inalcanzable, el acto puro, al que tiende todo el proceso de lo real. De manera que el mundo para Aristóteles es eterno e increado. $\mathrm{El}$ pensador estoico tampoco entiende o siente el mundo como un proceso finito e irrepetible sino más bien como algo repetible en ciclos infinitamente (el eterno retorno). En el Platonismo medio, esto es, en el Platonismo de los comienzos de la era cristiana, se concibe ya que las ideas no son autónomas sino pensamientos de Dios (del creador), pero se sigue postulando una materia pre-existente. Si las ideas, que son pensamientos de Dios - se argumenta- son eternas, ¿cómo Dios, que es la bondad, podría hacer cosas pasajeras a partir de ideas eternas? Y si el mundo no es pasajero ¿cómo podría entonces tener comienzo? Así pues, aunque Dios ha creado el mundo en la materia, aun este acto es intemporal, ya que de otro modo tendría que concebirse a Dios sin su perfección antes del comienzo del mundo: un Dios que no ha creado todavía no es creddorlO'Estedrazonamientos-aparentemente simple- tuvo repercusión incluso entre los cristianos. Orígenes - uno de los más brillantes teólogos cristianos de la patrística griega- era incapaz de concebir a la vez un Dios eterno y un comienzo temporal de lo creado. Si el creador es eterno, ¿cómo podría concebirse el comienzo de la creación, esto es un Creador antes del comienzo de la creación? La cosa es tan absurda - decía- que tendríamos que admitir también que podría haber un "rey sin reino" o un "padre sin hijo". Orígenes piensa, que aun. que este mundo que vivimos es mudable y corruptible, siempre habrá y siempre ha habido un mundo. Los mundos pasan y se renuevan sucesivamente después de grandes catástrofes. Dios hace nuevos mundos, no los crea; la creación es eterna. Orígenes es cristiano, qué duda cabe, pero su pensamiento está sujeto todavía a las concepciones básicas del pensamiento griego, como todos los de la Escuela de Alejandría. Se halla aún ganado por los ideales griegos de perfección: simetría, proporción, finitud. Su idea de Dios es la representación de un arquitecto que modela de acuerdo a peso, número y medida. No penetró, ni pudo penetrar, a consecuencia de su conformación mental helénica, en el 
mito de la creación judeo-cristiana. Lo que le faltó tamblén fue una idea correcta del tiempo y lo temporal.

Es mérito de San Agustín haber distinguido por primera vez, con claridad admirable, entre lo temporal y lo eterno, lo fugaz de lo terreno y la permanencia del ser de Dios. Las cosas de este mundo vienen del no ser y corren hacia el no ser (tendere non esse). La estructura visible de la criatura discurre entre lo que no es todavía (nondum) hacia lo que ya no es (non iam) por un presente escurridizo. La dirección del tiempo se despliega en el alma y no en las cosas como parecería, porque las cosas pasadas en verdad ya no son y las futuras todavía no son, y las presentes a poco que se analicen se desvanecen en el pasado, pues el presente es una minutissima pars momenti que a poco que lo pensamos ya es pasado.

Ahora bien, el tiempo en realidad es una distentio animae con tres direcciones: el presente en el alma de las cosas pasadas (memoria), el presente en el alma de las cosas futuras (exspectatio) y la intuición del presente (contuitus). El cristiano Agustín no ve las cosas estabilizadas en esencias permanentes como el filósofo clásico griego y, después, el escolástico del s. XIII y siguientes bajo el influjo de la filosofía de Aristóteles. El mun. do para Agustín es un flujo incesante. Por eso se ha querido ver en la teoría agustiniana de la temporalidad un antecedente de la teoría de la durée de Bergson. Pero nada más alejado de la verdad. Al paso que para Bergson la durée es la realidad misma, para Agustín el fluir temporal es una cuasi nada; la realidad en cambio es el ser que permanede.

El mundo que es de naturaleza temporal, ha tenido un origen, pero no precisamente en el tiempo, pues entonces habría que preguntarse qué ha transcurrido antes en ese tiempo en que no ha habido mundo. $Y$ obviamente no hay tiempo si nada transcurre. El mundo pues no ha sido creado en el tiempo, sino con el tiem. po. Y es que el tiempo, cunque no está condicionado por el movimiento, es tiempo sólo de lo que cambia y muda. Dios que es el ser (yo soy el que soy, es la expresión de Dios en su revelación a Moisés), no cambia ni muda. Por eso es que es eterno. Esta distinción con parecer simple no se hizo antes de San Agustín.

Agustín es el primer pensador cristiano que ha esclarecido el misterio de la creación. Lo que no quiere decir que haya fundado racionalmente este concepto. Agustín se mueve inicialmente de la fe hacia la razón. El credo ut intelligam va a ser una característica y un leitmotiv del filosofar cristiano a partir del obispo de Hipona. De allí que con justicia se llama a San Agustín el primer filósofo cristiano.

Si bien la criatura es en su estructura un ser temporal que fluye incesantemente en el tiempo, interiormente empero es uni- 
dad por la memoria. La memoria por otra parte es capaz de re velar el ser propio que en contraste con el ser de Dios eternamente oculto, se intuye en el interior del hombre. La criatura en sí misma es nada, pero en su relación con Dios es ser. De suerte que el fundamento de esta unidad constituida en la memoria es el ser. La consistencia de este ser es la imitatio de las ideas en la esencia de Dios. Se comprende entonces que en el fondo del ser de la criatura haya un afecto permanente hacia la perennidad en Dios. "Tu excitas, ut laudere te delectet, quia fecisti nos ad to et inquietum est cor nostrum, donec requiescat in te" (Conf. I, l). La inquietud por el ser es la inquietud por la verdad, ya que para Agustín la verdad es lo que es. Pero la verdad no está afuera, en lo temporal, en el fluir y en el cambio, sino en el interior. "Noli foras ire, in te redi, in interiore hominis habitat veritas". No es que Agustín busque en el interior, en el Cogito, las ideas innatas o las verdades eternas. Sino que en primer lugar la interioridad es el camino hacia el ser.

La vuelta a la interioridad parece estar motivada en San Agustín por la incertidumbre del conocimiento del mundo exterior. El escepticismo de Agustín tiene antecedentes históricos en los académicos. Por otra parte no debemos dejar de remarcar que en el s. IV, en la decadencia del Imperio, se siente muy angustiosamente la fugacidad de lo visible. A partir de la duda del conocimiento del mundo externo Agustín arriba a la evidencia del Cogito y con ello a la trascendencia de la interioridad. Doce siglos antes que Descartes, Agustín afirma "si enim fallor, sum" (CD xi, 26). Si me equivoco, soy, si dudo, soy. Páedelque mi representación del mundo sea falsa una eosales empero indubitable: que yo tengo la representación del mundo. Con esto Agustín no sólo reduce la certidumbre al pensar y al sujeto pensante, sino que llega a la evidencia de la conciencia. De esta suerte Agustín parece un cartesiano avant la lettre, si no un precursor lejano de la filosofía moderna. En efecto, en el pensar moderno se establece, según decir de Hegel, el pensar como principio, el pensar que sale de sí mismo, esto es, la interioridad. "Das allgemeine Prinzin ist jetzt, die Innerlichkeit als solche festzuhalten, die tote Äusserlichkeit, Autorität, zurückzusetzen, für ungehörig anzusehen. Nach diesem Prinzip der Innerlichkeit ist nun das Denken, das Denken für sich, die reinste Spize des Innersten, diese Innerlichkeit das, was sich für sich jetzt aufstellt. (Vorl. über Geschichte der Philosophie, Werke XIX, 1928, 328). Pero San Agustín no es un hombre de la época moderna. Trece siglos no corren en vano. Su pensamiento se mueve dentro de otros horizontes y está motivado por otros intereses e inquietudes que los del hombre del racionalismo del siglo XVII. El Cogito no es para Agustín la piedra angular del conocimiento seguro a partir de la cual se puede edificar un 
sistema coherente y cerrado de proposiciones verdaderas referentes a la realidad del universo. El Cogito tiene para Agustín alcances a la vez más modestos y más profundos que los del racionalismo. En primer lugar, persigue demostrar por este medio que el escepticismo tiene sus límites. En segundo lugar, la evidencia del Cogito sirve para añadir una certidumbre más a las de la fe. El Cogito es pues un momento del pensamiento agustiniano, pero no es meta ni eje sobre el que gira el pensar y menos la inquietud de San Agustín.

"Deja el exterior, adéntrate en ti mismo, anda en tu misterio, en tu espíritu" (In job Tret. 93. 10). Al tornarse hacia sí mismo, al interior, Agustín no encuentra como Descartes una estructura de pensamiento, "la pensée qui se connoit soi même", la "chose qui pense", sino el espíritu. Ahora bien, este espíritu o alma no es una substancia, una res cogitans, sino una profundidad insondable, en cuyo fondo late un anhelo de felicidad perdida, de un Dios que se busca porque se tiene un vago recuerdo efectivo de él, como ese querer de no se sabe qué. "No me buscarías si no me hubieses ya encontrado", clamaba Pascal trece siglos después repitiendo un motivo agustiniano. No es por el cuerpo, sino por el espíritu que el hombre es hecho según la imagen de Dios. En el espíritu se reconoce al Creador"' (loc. cit.). El espíritu - que es la interioridad (el hombre interior) - es la imago Dei y por él conocemos a Dios.

Agustín no anda preocupado por una prueba racional de la existencia de Dios. Ni a partir de la consideración del mundo exterior, como SantoJomás (prueba cósmológica). Ni a partir de la dea de Dios como Anselmo de Aosta (prueba ontológica). El mundo exterior no puede servir de fundamento para la intelección de lo real, ya que es una dispersión del tiempo. Y la razón en sí misma es sólo instrumento de conocimiento, que opera profundamente sólo cuando es movida por la fe o por una visión. Es en el misterio de la fe en que se da el salto a lo trascendente, a lo otro. $\mathrm{Y}$ en esto Plotino y Porfirio le han abierto la ruta.

\section{La trascendencia}

Se ha hablado y escrito con frecuencia que la filosofía y el dogma cristianos han tomado la idea de trascendencia divina de la filosofía griega. Nada más falso. La idea de trascendencia de los griegos se funda en una concepción de la realidad totalmente diferente, como se probará más adelante. Pero el cristianismo tampoco es tributario en este punto de la tradición judía. Según el judaísmo, las cosas que existen en el seno de Dios son las mismas que aparecen, sin que haya diferencias cualitativas entre unas y otras. No se distingue en la tradición judía entre lo encubierto y lo que aparece, de igual modo que el objeto en la 
oscuridad no cambia cuando se hace visible por la luz. En consecuencia tampoco se distingue entre lo espiritual y lo sensible, lo infinito y lo finito. El Mesías no es la encarnación de Dios sino su aparición, cosa diferente al misterio de la Encarnación. En el pensamiento judío no están pues las raíces del dualismo cristiano. (Cf. Harnack. Lehrbuch d. Dogmengeschichte, I, 797). La filosofía griega clásica tiene la pretensión de que la realidad es plenamente inteligible. Algo más, que en su totalidad es un conjunto perfecto, simétrico y limitado, un cosmos como emergido del caos y tallado según proporción y equilibrio, con una parte inteligible y otra sensible. No vamos a hacer las distinciones internas de esta filosofía (platonismo, aristotelismo, etc.). Quede sólo registrado que la noción de trascendencia que aquí se establece es la de lo inteligible con respecto de lo sensible. Esta división de la realidad sólo supone una cabal intelegibilidad de lo real. Recuérdese no más que para Platón, el mundo de las ideas es cognoscible por el alma porque ésta es semejante a aquéllas. Y para el griego vale eso de que lo semejante conoce lo semejante. La idea de trascendencia cambia reciến en el período helenístico-romano con el Neoplatonismo a partir de Plotino. Los neoplatónicos señalan una zona de la realidad -determinante y fundante del restocuya aprehensión por los instrumentos de la razón y de la inteli gencia es empero imposible. El Uno no sólo está más allá de toda inteligencia o noûs, sino incluso de todo ser. Lo que abre posibilidades a la experiencia mística. Porfirio elabora una teología especulativa de gran coherencia. El Uno, aunque fuera de toda posibilidad de aprehension directa por el Cintelecto, es accesible sin embargo por un proceso de pensamiente analógico, animado y sostenido por una ascesis intelectual rigurosa. Porfirio sostiene que hay un órgano de conocimiento discursivo para distinguir lo verdadero de lo falso. Pero hay también otro órgano que en un nivel ontológicamente superior distingue lo verdadero de lo falso. Este último opera fundado en el parentesco con la divinidad. Por esta y otras cosas han afirmado Theiler y Dörrie que es Porfirio antes que Plotino el que influye en San Agustín o, mejor, que Porfirio es el mediador entre Plotino y Agustín (1). Por la radical ininteligibilidad de lo divino se establece ya con el Neoplatonismo de Plotino y Porfirio, según Dörrie, orgánica y enfáticamente el dualismo místico. El dualismo místico se expresa en la oposición: lo de aquí y lo otro. Dios, el Uno, es lo extraño no obstante ser fuente

(1) W. Theiler. Porphyrios und Augustin. Schriften der konigsberger Gelehrten Gesellschaft 10, (1933). H. Dörrie. Porphyrios als Mittler Zwischen Plotin und Augustin (Miscellanea Mediaevalia I). Berlin, 1962. 
de todo lo real. Esta presencia de lo ausente en la experiencia mística, que es más sentida que entendida, es un elemento nuevo en el pensamiento filosófico. En el período clásico el nivel humano de los dioses no admitía una superracionalidad divina. Pero en el período helenístico romano se produce un proceso de interiorización en el pensador que se agudiza en las postrimerías del Imperio. Proceso que lleva el pensamiento a sus límites y a concebir lo divino como lo realmente otro.

Sin embargo, este dualismo místico tiene límites ontológicamente borrosos. El Neoplatonismo asume la idea de que lo divino es inmanente en todo lo real, lo que torna insostenible el dualismo ontológico. Tarde o temprano el inmanentismo deviene en panteísmo. El misticismo neoplatónico supone en efecto una participación de lo divino en el hombre y la consecuente capacidad de éste para liberarse. Porfirio afirma que la existencia pecaminosa se aleja de Dios y la pura se acerca. La posibilidad de salvación depende del hombre y de su esfuerzo, lo que supone la inmanencia divina.

El dualismo cristiano se define en cambio por una radical trassendencia de lo divino. La alteridad divina supone la separación abisal de Dios con respecto de lo creado. No se admite la inmanencia divina ni que la salvación sea por el esfuerzo personal o por méritos propios. Pero esta trascendencia no implica indiferencia de Dios - como lo pensaba Epicuro. El Dios cristiano es el Dios del amor y su relación con el mundo se explica -y esto lo deja bien establecido Agustin-A por la Gracia. Que la alteridad, el dualismo ontológico se asienta definitizamente como pensar filosófico recién a partir de San Agustín, es ahora fácil de comprender. No en último lugar es responsable de ello el desarrollo de la filosofía neoplatónica. Los pensadores de la Patrística griega no pudieron fundamentar esta trascendencia. Dominados aún por la concepción griega de la realidad, tenían la representación de un Dios intelecto, intellectus divinus, cuya acción se regía antes por la razón que por la voluntad y el amor. Instintivamente respondían con el rechazo a todo lo irracional. El límite de la realidad no era entonces lo infinito sino el desorden, el caos. Por eso es que los primeros intentos de explicación del misterio cristiano no están exentos de gnosticismo. Agustín concibe un dios -el Dios de los cristianos - como lo realmente otro. Y en esta alteridad se funda su trascendencia. Su relación con el mundo no se explica ni por la razón (nada es justo frente a Dios), ni por la perfección (no hay suficiente belleza frente a Dios) sino por la voluntad, que en sí misma es impenetrable: "Qui autem dicit, quare voluit facere coelum et terram? magis aliquid quaerit quam est voluntas: nihil autem magis inveneri potest" (gen c. man. I, ", 4). 
Si la relación de Dios con el mundo es por la Gracia, la del hombre con Dios es - al menos inicialmente- por la fe. En la fe se expresan a la vez los límites de la inteligencia (de allí la expresión de San Pablo: la fe es el escóndalo de la razón) y la radical heterogeneidad entre Dios y el mundo, entre el creador y lo creado. Kierkegaard ha explicado modernamente la alteridad cristiano-agustiniana: ". . . indes ist Glauben das 'ganz andere' Jenseits des Denkens. Zwischen ihm und Denken liegt das 'Paradox', die 'Umwendug', das 'Argernis' (GW VI 8-100), weil der Glauben ist kraft des 'Absurden' (GW III, 29)".

Habíamos dicho antes, que según la filosofía griega clásica, las cosas tienen su naturaleza y gozan de perennidad en sus esencias. Aun en la Escuela estoica que se caracteriza por su severidad ética antes que por su amor a la naturaleza y a las cosas del mundo, vemos una preocupación por lo perenne en lo sensible y en lo individual. Afirman los estoicos que las cosas vuelven una y otra vez exactamente en las mismas formas y condiciones. Para los antiguos, presente y futuro son elementos constitutivos del pasado y el tiempo discurre sólo para desarrollarlos, para mostrarlos. Estas ideas no son privativas de los paganos, en los primeros siglos de la era cristiana. Hemos visto que aun Orígenes sostiene el renacer incesante de los mundos y lo curioso es que busca apoyo en el texto sagrado para sostener su tesis. En el Eclesiastés leemos en efecto: lo que ha sido será de nuevo, lo que ha acontecido acontecerá otra vez. Nada nuevo hay bajo el sol. Si hubiese algo de lo que se diga: He ahí algo nuevo, tiempo ha que ha ocurrido en edades pasadas (Ecld It 9-1I).

Para San Agustín al contrario las cosas visibles no son propiamente, sino que acaecen. Vienen del no ser y pasan al no ser. Las cosas temporales se extienden - por decirlo así- entre dos nadas.

La característica de lo temporal es su irreversibilidad. En la Enarratio del Salmo 38 Agustín confiesa con tristeza la disolución de nosotros mismos en la nada del tiempo: "Mira" -le dice a su interlocutor- lo que acaba' de suceder: somos más viejos que cuando comenzamos a dialogar. Tú no percibes que tus cabellos han crecido. Sin embargo, mientras estás de pie, haces algo y hablas, tus cabellos crecen. Y no crecen en un momento. El tiempo nos mina y fuga irremediablemente. Tu pasas y tus hijos pasarón después de ti". En un sermón habla Agustín en forma patética de esta nuestra existencia que discurre y se acaba. "Con el andar del tiempo pareciera que nuestra vida se alargara. Pero qué desengaño. Tengo 46 años -dice Agustín- y sólo de una cosa estoy seguro: que me quedan 46 años menos de vida de los que el creador me ha concedido" $(38,3,5)$. El mismo te$\mathrm{ma}-\mathrm{y}$ como si se tratase de su preocupación vital más honda- 
lo toca en la Ciudad de Dios en un pasaje bastante citado: "Desde el momento que se comenzó a existir en este cuerpo corruptible, nada sucede en él que no sea para la muerte. Pues durante el discurrir de esta vida - si es que a ella se le puede llamar vida- las vicisitudes de nuestra existencia nos traen cada vez más cerca de la muerte. Nadie hay que después de un año no esté más cerca de la muerte que el año anterior, mañana más que hoy, hoy más que ayer, y en este momento más que en el inmediatamente anterior. El tiempo que se vive es un tiempo robado del que nos queda por vivir. Diariamente se toma de lo que aún queda. Así pues, el tiempo de la vida no es más que una carrera hacia la muerte... Currum ad mortum (C.D. XII, 10). Lo que nos recuerda los admirables versos de Rilke:

Denn wir sind nur die Schale und das Blatt.

Der grosse Tod, den jeder in sich hat, das ist die Frucht, um die sich alles dreht.

\section{(Das Stunden-Buch)}

Pues no somos más que cáscara y hoja.

La gran muerte que cada uno en sí lleva, es el fruto en torno al cual todo gira.

Hoffmann (Platonismus und-christliche Philosophie, 1960) ha afirmado que la filosofía de la historia no procede de los estoicos, tampoco de Agustín, sino de ambos. Allpaso que los primeros sostienen la idea de que el mundo notiene término, el segundo afirma la dimensión lineal de lo temporal. Pero esta afirmación de Hoffman es errada. En la mera unidimensionalidad e irreversibilidad de lo temporal no se funda la filosofía de la historia. San Agustín es el primer filósofo de la historia no sólo porque descubre la temporalidad del mundo $y$ del ser del hombre, sino por que en el acaecer de la historia se le hace transparente la eternidad. Para el cristianismo, el reino de Dios, que está siempre por venir, está ya al mismo tiempo en nosotros. Pues la verdadera eternidad no es la que nos espera después de muertos y al cabo de la historia, en el Juicio Final, sino la que está eternamente presente y dura todos los tiempos. De esta manera, la eternidad es el verdadero contenido de la historia. Sin este contenido el discurrir de las cosas y la historia toda no tendrían sentido.

De esa suerte vemos que el sentido de la historia no sólo está dado por el Juicio Final al cabo de los tiempos, sino por el permanente desgarramiento del ser del hombre: entre el hombre exterior en que toda huella del espíritu ha desaparecido en lo trágico y lo grotesco de la carne, y el hombre interior 
en que la carne espiritualizada sirve para la aparición del espíritu -que es, como dijimos, la Imago Dei. San Agustín concibe la Ciudad de Dios como opuesta a la Ciudad Terrena. Pero no porque la primera deba reemplazar necesariamente a la segunda, al fin de los tiempos. La Ciudad Terrena se convierte en el reino de la paz, felicidad y el amor aun en el tiempo presente.

Es incuestionable, empero, que el fin de la historia que compete al género humano, es el que promete la unidad y perfección del destino de todos los hombres: la vida eterna y la felicidad. De esta suerte, el sentido propio de la historia es el fin al que tiende el desarrollo lineal del proceso histórico. Recordemos de paso que para Marx la historia termina también en la paz de la sociedad sin clases, última estación de la historia en la que el hombre será verdaderamente libre. Este fin marxista de la historia se inspira sin duda en la filosofía de la historia agustiniana. Aunque hay una diferencia que importa destacar. Para Marx la historia es el resultado de la acción del hombre que persigue sus propios objetivos y fines. El fin de la historia -sacralizada en San Agustín- Marx lo ha secularizado. El desarrollo de la historia y el fin de ésta es sólo cuestión de los hombres y concerniente a lo humano. El hombre ha asumido modernamente el rol de Dios en la historia.

Casi todas las filosofías de la historia -que en el fondo son profecías - tienen algo de común: la idea de que el hombre en una u otra forma ha caído en una suerte de pecado original. El capitalismo burgués haocösificade allhombrea.So ha vuelto una mercancía y, en consecuencia, lo ha enajenado "según Nietzsche, Sócrates y el cristianismo han desviado al hombre hacia el servilismo y la esclavitud; los racionalistas pensaron que el pecado del hombre es su ignorancia. Todas estas concepciones tienen de común la afirmación de que el hombre en su esencia se ha traicionado y ha caído en una encrucijada de la que requiere salir para salvarse. El objetivo es revelar la verdadera esencia del hombre, que para el marxismo ocurrirá después de la lucha final contra la bourgoisie y con el establecimiento de la sociedad sin clases. Para el Anticristo Nietzsche, el hombre se ha vuelto esclavo de sus prejuicios morales. La represión de que habla modernamente Marcuse es la causa de la infelicidad del hombre, de su desasosiego y de su agresividad. Todas estas profecías modernas suponen que el hombre recobrará su esencia por sus propios medios.

Este sueño del hombre no es de ahora sino de siempre, con la diferencia de que los salvadores eran antes los dioses a los que se veneraba. Desde hace algún tiempo, desde el Renacimiento, se habla de una salvación del hombre por el hombre; el paraíso 
se ubica en este mundo; recuérdese las utopías de T. Moro, y Campanella, el imperio de la razón que animó a la Revolución Francesa, el progreso indefinido de Comte, la liberación del trabajo por el desarrollo industrial (Automación y Cibernética). El hombre ha soñado y soñará siempre en un mundo mejor, como si el sueño fuese testimonio constante de su fracaso. El hombre sigue esclavo de sí mismo, acaso más que antes, preso de fuerzas que no controla, de pasiones que lo dominan, de ambiciones destructivas que con el perfeccionamiento de la técnica moderna podrían significar el fin secular de los tiempos. San Agustín no creyó nunca que el hombre alcanzaría la salvación por sus propios medios. Algo más, no pensó que la historia transformaría al hombre y la vida del hombre mejoraría por efecto del Cristianismo. Quién no recuerda los pasajes del Evangelio de San Mateo 24, 4-8, 10-13 cuando los discípulos le preguntan a Jesús: "¿Cuál será el signo anunciador de tu retorno y el fin del mundo?". Cristo responde: "Tened cuidado que nadie os engañe. Pues muchos vendrán en mi nombre y muchos os engañarán. Escucharéis de guerras y de rumores de guerras. Pero no os asustéis. Pues todas estas cosas deben suceder. Pero no es todavía el fin. Pues una nación se levantará contra otra y un reino contra otro y habrá hambre, pestilencia, terremotos y todo esto es sólo el comienzo del cambio. Y aparecerán muchos falsos profetas y muchos embaucadores... Y a causa del desengaño, el amor de muchos se enfriará. Pero quien resista hasta el fin, se salvará".

Los que resistan a la presión, que con el correr de los tiempos será más dura, se transfigurarán en la vida feliz. Es curiosa una vez más la semejanza entrellas profecías secularizadas y la sacralizada de Agustín. El hombre no se salvará a menos que se transfigure, sea por la fe en San Agustín-o por la desalienación. El fin de la historia es entonces la salvación del hombre. Por más desengaños y frustraciones, el hombre siempre soñará con un destino mejor. El alma sin esperanza - decía Gabriel Marcel-se seca y muere. Y un filósofo marxista, Ernst Bloch, ha titulado su obra capital: Das Prinzip Hoffnung (El principio esperanza). Todo como si la esperanza fuese la esencia del ser del hombre. 